Vol. 6(1), pp. 1-9, January 2014

DOI: $10.5897 /$ IJNM2013.0107

International Journal of Nursing

ISSN 2141-2456 (C) 2014 Academic Journals

http://www.academicjournals.org/IJNM

and Midwifery

Full Length Research Paper

\title{
The eating experiences of patients hospitalized in a muscular dystrophy ward in Japan: A phenomenological study
}

\author{
Emiko Ishida \\ Graduate School of Medicine, Division of Health Science, Osaka University, 1-7 Yamadaoka, Suita, \\ Osaka, 565-0871, Japan.
}

Accepted 18 November, 2013

\begin{abstract}
The aim of this study was to explore the life experiences of patients hospitalized in a muscular dystrophy ward in Japan, with particular focus on their eating experiences. Participant observation and unstructured interviews were conducted, and data analyzed by employing Merleau-Ponty's phenomenology. Nine patients agreed to participate in this study, although only five were included in the analysis. The overarching theme of patients' eating experiences was "cultivating new eating habits," which patients nurtured according to their surrounding environment and in response to the increasing medical support and their progressive functional decline. The new eating habits were organized into five sub-themes: "moving my body at my own will," "eating independently," "learning to accept the percutaneous endoscopic gastrostomy tube," "an alternative to having meals" and "using tube feeding." These new eating habits engendered in patients a "richer," multisensory perception of eating, one where they do not merely rely on taste.
\end{abstract}

Key words: Muscular dystrophy ward, patients, eating experiences, phenomenology.

\section{INTRODUCTION}

Muscular dystrophies are a clinically, genetically, and biochemically heterogeneous group of disorders that share distinct clinical-pathological features on muscle biopsies (Emery, 2002). Different muscle groups are affected depending on the type of muscular dystrophy, with Duchenne muscular dystrophy being the most common; this is an X-linked recessive neuromuscular disorder, occurring in childhood (Dubowitz, 2004).

Most previous studies on muscular dystrophy have been on the pathophysiological and genetic mechanisms behind this disease (Nätterlund and Ahlström, 2001). On the other hand, because the progression of muscular weakness characteristic of the disease causes numerous problems in the everyday lives of those who suffer from it (Ahlström and Gunnarsson, 1996), some researchers have investigated the many types of support offered to muscular dystrophy patients. In recent years, the survival rates of young men with Duchenne muscular dystrophy have increased due to the development of mechanical ventilators and other medical technology. This has led to research on the quality of life of patients supported by this technology (Kohler et al., 2005; Narayanaswami et al., 2000). Furthermore, research on patients' own experiences, as opposed to those of the parents, is becoming more common. To investigate patients experiences directly, researchers have employed a number of methods, including phenomenological methods (Nätterlund and Ahlström, 1999; Pehler and Craft-Rosenberg, 2009), inductive content analysis (Boström and Ahlström, 2005; Nätterlund et al., 2001), ethnographic case studies (Gibson 
et al., 2007, 2009), and Ricoeur's theory of interpretation (Dreyer et al., 2009).

In Japan, muscular dystrophy wards are the typical method of care for patients with the disease, which the government first implemented in 1964 with a single longterm care facility. This has since grown to 2,500 beds in 27 areas across Japan. Recently, advances in life sustaining and assistive technologies such as mechanical ventilators have increased the life expectancy of these patients. In 2007, around 2,066 patients were living in muscular dystrophy wards; $56.7 \%$ of these patients were on artificial ventilator support (Tatara and Jino, 2008).

Most muscular dystrophy research in Japan has focused on the development of therapies and lifeprolonging treatments. In addition, research groups consisting of staff from muscular dystrophy wards have begun investigating the problems characteristic of patients living in those wards, such as psychological problems, particularly in young patients (Masuda, 1993; Okumura, 1997), control of complications, and issues specific to severely impaired patients (Omoto et al., 2010). However, because of the widespread use of mechanical ventilators, some researchers have recently begun to explore ways to improve the prolonged hospitalized life of patients with muscular dystrophy by focusing on patients' life purposes and quality of life (Kawai et al., 2005; Konagaya et al., 2006). Nevertheless, these studies were conducted from the biomedical and technical perspectives; in contrast, few studies have considered how patients live in these wards, despite all of the necessary supports. More recently, several researchers conducted studies on patients' views of living with muscular dystrophy in Japan (Tsujino, 2005; Ito, 2008, 2010; Ishida, 2012).

In this study, focused was on describing the life experiences (particularly those related to eating) of hospitalized patients in a muscular dystrophy ward, because in the initial fieldwork phase of this study, some of the participants confirmed that one of their particular pleasures was eating. Furthermore, many participants talked about their memories of eating experiences and often seemed to be particularly lively during mealtimes at the ward. Therefore, it was thought that the experience of eating might be an important aspect of their hospitalized lives.

In Japan, previous research on the eating behavior of muscular dystrophy patients has often centered on reducing the risk of pneumonia by aspiration and suffocation because of their dysphagia (Fujihara, 2010; Yoshiga et al., 2010). These studies led to the creation and publication of a recipe book for muscular dystrophy patients (Nutritional and Physical Sectional Committee, 2007). Above all, previous studies have taken a particularly medical perspective in studying the eating behavior of muscular dystrophy patients, focusing mainly on ways to help them eat as their motor functions decline. However, few researchers have considered eating experiences experiences from the patients' perspectives, such as how they eat their meals daily. Similarly, no attempt has been made to describe the experiences of patients who must be fed by a tube because of their severe muscular impairment.

Thus, the purpose of this study is to describe the life experiences of those patients who have lived in a muscular dystrophy ward since their childhood, focusing on their eating experiences and also to get valuable suggestions for nursing practice. Providing nurses with deeper philosophical insight into the meaning of eating for muscular dystrophy patients would lead to enhancing patient care in a situation where technical nursing skills based on medical knowledge are more emphasized. To describe these experiences and fully understand their meaning for patients, it would be necessary to focus particularly on individual patients' own perspectives in the context of how they try to eat their meals daily in the ward, rather than by developing a general theory created by analyzing the experiences of a large sample of patients. This is on a phenomenological approach was decided.

\section{METHODOLOGY}

In this study, the eating experiences of patients in a muscular dystrophy ward were described by employing the concepts of MerleauPonty's phenomenological approach. As discussed, in previous studies that took a medical perspective in examining patients in muscular dystrophy wards, patients reported feeling that they had lost their ability to live by themselves because of the increasing muscular weakness and related symptoms of the disease, and thus they often experienced considerable anxiety. In the present study, a number of patients observed and interviewed were observed, and while they reported feeling anxious at times, most did not remain so. The French philosopher Merleau-Ponty $(1945,1962)$, inspired by Husserl, claimed, "Phenomenology ... does not expect to arrive at an understanding of man and the world from any starting point other than that of their "facticity". However, nurses in muscular dystrophy wards tend to view patients as static beings, often taking a perspective wholly focused on the scientific and medical aspects of patient care; this is because their primary responsibilities are providing medical care, particularly with recent advances in medical technology. In other words, nurses do not attempt to see patients' "facticity." That is to say, by focusing solely on treating patients, nurses are difficult to clearly see patients' "facticity". For this reason, Merleau-Ponty's approach to phenomenology was suitable for exploring muscular dystrophy patients' experiences.

Merleau-Ponty $(1945,1962)$ also claimed, "All my knowledge of the world, even my scientific knowledge is gained from my own particular point of view, or from some experience of the world without which the symbols of science would be meaningless". That is, he insisted that our primary experience of the world is not from a positivist, scientific viewpoint, but instead from a singular, personal point of view centered on our actual experience of the world. From this perspective, patients were viewed not as static beings as seen from the medical perspective, but as dynamic entities formed of their own subjective points of view.

Furthermore, although these patients were confined to the world of the muscular dystrophy ward, they were still surrounded by many people, events, and ideas - much the same as in the outside world, and were in constant interaction with such ever-changing phenomena 
and were in constant interaction with them. Merleau- Ponty (1945, 1962) claimed that, "the phenomenological world is not pure being, but the sense which is revealed where the paths of my various experiences intersect, and also where my own and other people's intersect and engage each other like gears". That is, people's "lived experience" is constituted of their interactions with other people and phenomena. Therefore, it is found that in order to fully understand patients' eating experiences, focus must not merely be on their anxiety and struggles, but include all of their life experiences in all of the surrounding contexts of their lives namely, what each patient's experience of eating means within his or her individual context.

Thus, in the present study, each patient was viewed as a singular entity with his or her own life and unique context, rather than the more stable, generalized view of patients as people suffering from anxiety and struggling to live in a muscular dystrophy ward. In this way, each patient's actual lived experience could be described.

\section{Settings and participants}

Data were collected at the muscular dystrophy ward of a 300-bed medical center belonging to the National Hospital Organization, located within a rural area in Japan. A nurse manager volunteered to make initial contact with participants in the muscular dystrophy ward, except for patients with severe impairments, before data collection began. After receiving approval for this study from the ethics committee of the hospital, the study was conducted between October, 2011 and September, 2012. Direct recruitment of ten participants was done from the ward and one patient in them was rejected. The inclusion criteria were being hospitalized in the muscular dystrophy ward and being over 18 years of age. In addition, they had to be able to speak Japanese and understand the interview questions and research purpose.

Nine patients, ranging from their teens to their fifties, agreed to participate in this study. This age range allowed for considerable variation in experiences and demographics. One participant passed away during the course of the study. All were men. One participant was receiving invasive ventilation $24 \mathrm{~h}$ per day through a tracheotomy, while another was receiving noninvasive positive pressure ventilation (NIPPV), also $24 \mathrm{~h}$ per day. Four were receiving NIPPV either only when lying down after lunch and dinner or only at night. Four participants were using a percutaneous endoscopic gastrostomy (PEG) tube. One participant was fed solely by the tube, while two participants ate only their lunch by mouth. The last participant only used the PEG tube while taking his medication.

For this study, the interview data and field notes of five participants was used, Participants $A, B, C, D$, and $E$, but focus was mainly on two: Participants $A$ and $B$ because they were most willing to talk about what eating meant to them in light of their declining motor functions and their experiences of using the PEG tube. Unfortunately, the other three participants (C, D, and E) did not speak much about eating, and thus only a limited amount of data could be collected from them; however, their experiences could be analyzed to complement the structure of the two participants' experiences. Furthermore, the data of the other four participants, not analyzed in this study, could be analyzed in the same way. Finally, for the subsequent analysis, information from the field notes on a nurse in the ward was also included. One of the attending nurses and a mother of one participants appeared.

\section{Data collection and analysis}

Data collection methods during the fieldwork phase of this study included unstructured interviews and observation of the participants in the ward, recorded via field notes. In line with Merleau-Ponty's aim $(1945,1962)$, "to return to the world of actual experience which is prior to the objective world", no structured methodology related to the medical or general perspectives was employed in collecting the data for this study. Because unstructured free dialogues are more appropriate for drawing out patients' detailed and indepth experiences. In the unstructured interviews, data from daily conversations with participants at their bedsides was recorded; often posing questions about what was observed. These interviews were audiotaped when given permission.

For the participant observation, attention was paid to their day-today activities by observing them at their bedsides. Furthermore, staff members were observed throughout the day as they cared for their patients, performing activities such as suction, moving patients to their power wheel chairs, and conducting physical and occupational therapy, while also paying attention to how staff conversed with patients. their daily life routine was described and made sure to keep observations from patients' perspectives, which would allow to view the patients not as static beings, but as "a subject destined to the world" (Merleau-Ponty, 1945; 1962).

In analyzing the data, Merleau-Ponty's argument $(1945,1962)$ of "... a figure on a background..."; that is, "The perceptual 'something' is always in the middle of something else, it always forms part of a 'field"' was referred to. In other words, there was need to consider the overall structure of each patient's experiences; therefore, focus was on the modalities of patients' experiences, such as their "unique mode of existing" and their "unique manner of behavior towards others and the environment." Furthermore, a recorded of each patient's manner of speaking, such as when they were hesitant, faltering, or uncertain (e.g., using words such as "like," "so," or "seem"), rather than on the actual content of their experiences, was taken. By doing so, it was imagined that an abstract of some universal eating experience of patients in a muscular dystrophy ward could be taken. The following steps were taken to analyze the data.

1. First, the field notes and transcribed interviews were read in their entirety a number of times to obtain an overall picture of each patient's experience.

2. Then, all of the statements in the field notes and interviews related to eating, within their contexts was identified and described from each patient's perspective.

3. After reading the field notes and transcriptions several times, the overall structure of each patient's experience was conceptualized.

4. Through repeated analysis of the content, an extract of the themes of the eating experiences was done. Each theme was then scrutinized and refined to reflect a universal theme of life in the ward.

5. Finally, how each eating experience theme fit within the structure of each patient's overall experience in the ward was described.

For the past five years, there has been a study group on phenomenology for clinical practice, which consisted of nursing researchers, philosophers of phenomenology, anthropologists, clinical nurses, and so on. Various phenomenological methodologies have been studied and the aforementioned experts provided information on their guidance and oversight to be sure that the findings of this study well-reflect the eating experiences of participants. Furthermore, the study group helped to enhance the validity of the affirmations made by this analysis. In addition, a nursing researcher who specialized in phenomenological research supervised the whole analysis process. Before submitting this article for publication, the results were explained to the participants and all participants' permission to publish the findings was received. Furthermore, it was confirmed that the analysis results fully represented their ideas.

\section{RESULTS}

The main theme of patients' eating experiences that 
extracted was "cultivating new eating habits." Patients nurtured these habits according to their surrounding environments and in response to increasing medical support and their own progressive functional decline. The new eating habits were organized according to the following five themes that emerged from the data analysis: "moving my body at my own will," "eating independently," "learning to accept the PEG tube," "an alternative to having meals" and "using tube feeding." Using Merleau-Ponty's philosophy, I thought a great deal about how to describe the experiences of each patient and how I might identify a universal theme from each description in the analysis.

\section{Themes extracted from eating experiences}

\section{Moving my body at my own will}

One of participant A's eating habits was attempting to move his mouth and body at will. Participant $A$ is a man in his $30 \mathrm{~s}$, who was admitted to the ward in his second year of elementary school. When he was 16 years old, he required a sudden tracheotomy and started using an artificial ventilator. More recently, he has become almost entirely bedridden, save for his bath, which he takes two times per week; he also goes outside once or twice per year. He started using a PEG tube two years ago. Currently, he eats only his lunch by mouth. Although he said, "I enjoy eating," and looked forward to eating his lunch every day, he still found it difficult to move his mouth. One day, the lunch menu had curry, which was popular with both patients and staff. Participant $A$ also seemed to eat more than usual, so we engaged in the following conversation after he had finished his lunch.

Interviewer (I): How was it today? Wasn't it good?

Participant $A(A)$ : Yes, it was quite good today. It's fun! My body doesn't feel so tired.

I: Does your body feel tired when you find it difficult to eat?

A: I can't really move at will. It takes unnecessary strength to move some parts of my body.

I: Do you feel tired when the menu has your favorite food?

A: I can move the food in my mouth and chew it as I like [therefore, the menu was not related to his feeling tired].

At the beginning of our conversation, he mentioned the taste of the curry only briefly, and then said, "It's fun!" in reference to that day's lunch, because he could chew it. In this conversation, he mainly expressed how fatigue affected his motor functions, and thus his ability to eat. In this regard, the act of eating, for him, appeared to mean the ability to move his mouth at will to chew his food rather than merely the taste. The following day, I asked him, "Usually it's [the food] delicious, isn't it?" referencing his impression of the previous day's lunch.
A: The feeling of fun that I get from eating might be similar to the good feelings that other people get from exercising or moving their body. I just feel happy that I can move my body according to my will.

I: Do you mean that you care more about your ability to move your body or mouth than the act of eating itself, and that the act of eating is more like an instrument for you to achieve movements of your body parts?

A: It might be. Somewhere inside, I still feel the desire to move according to my own will.

The first sentence about the feeling of fun indicated that he had no experience of the "good" feeling of exercising or moving his body because he added uncertainty to this statement by saying, "might besimilar...." In addition, the phrases "exercising or moving their body" and "move my body" were likely recalled because of his feeling of "fun" from eating, indicating that motor experiences are what he associated most with eating. However, he often expressed these experiences by using a variety of terms (for example, "fun," "good," or "happy"), and while these terms are similar, their use suggests that his eating experiences are characterized by a wide range of feelings, thus, the act of "moving the mouth" might have had the same meaning for him as exercising or body movement had for others.

While talking about his desire to move, he remained uncertain, saying, "it might be..." and "somewhere inside." In this regard, it seems that in his daily life, he eats without any particular awareness of his desire to move. Furthermore, the words "somewhere inside" also suggest that his desire to "move" is no goal for the future, but a fixed quality of his self, weak enough to remain forever below his awareness. In other words, he will continue to eat according to this desire to move at his own will. In addition, he told me the reason why that he often tried to eat even when he found it difficult to move his mouth.

A: Well, maybe. I think that all sports players have a tough time. It's not exactly how players probably feel, but the feeling might be similar to how they must feel when they know that they can't play a game without practicing for a long time. Maybe it's similar, in a way, to how players feel happy when they play well in a game and their team wins.

He explained his reason for trying to eat, even when it was difficult to move his mouth, using sports players as an example. He claimed that despite the difficulty he had in chewing his food, he was happy when he was able to do it properly, much like how sports players felt after winning a game. Furthermore, his use of the phrase, "their team wins" suggests that he might consider his act of eating with assistance as somewhat of a team effort. That is, although Participant A had trouble in moving his mouth, he fought his disease along with the staff members of the ward by putting his entire body into the act of eating. 


\section{Eating independently}

Another eating habit that Participant $A$ had cultivated in the ward was to find a way to make it feel as if he ate independently, even though he was constantly assisted throughout his meals by an attending nurse. I frequently observed how Participant A was positioned on the bed for lunch, as well as how he was assisted by an attending nurse. The scene described was repeated daily.

Attending nurse 1 pushed the lunch cart to Participant A, after she had finished her morning care routine for the four patients in the same room as him and had started their feeding tubes for their lunches. Participant $A$, who had been in the right lateral decubitus position since that morning, was placed supine for his lunch. He said to the nurse, "Lift my head," and she lifted it a little. Then he said, "Glasses," after which she removed them, and "Legs," causing her to lift them up and place a pillow under them. This process of positioning him for lunch, always consisting of a combination of his voice and the nurse's actions, was repeated daily. After positioning him, attending nurse 1 sat down beside the bed on a stool and told him the lunch menu: "Today we have wontan noodles, yogurt, and the usual..." When she showed it to him, opening the cover (of the food container), he turned to look at it. nurse 1 then asked him, "Do you want to eat the wontan?" She then put some noodles in his mouth, just enough to comfortably fill his mouth. He then shut his eyes and chewed slowly, rolling the noodles in his mouth. Nurse 1 put her hand on his cheek and stroked it gently to help him chew and waited for another opportunity to put some food in his mouth with the chopsticks.

After I had observed this meal scene several times, I engaged Participant $A$ in the following exchange.

I: You eat lunch with assistance, but you're not so conscious of it, are you?

A: Yes, that's true. I feel like l'm just eating food by myself. When my mouth moves, all of my focus is on it. The assistant is like an assistant robot. Of course, they try to talk to me, but I don't really listen to them.

The phrases "I feel like ..." and "The assistant is like..." indicate that he understood that he was not eating by himself, and that he does not actually consider her an assistant robot. Furthermore, although he said, "I don't really listen to them," he still answered the nurse's question when she asked him if something had been lodged in his throat. Thus, he clearly does listen to the nurse assisting him in eating. However, it seems that he still considered eating to be an independent experience. This was evident from other conversations I had with him; for example, he said, "I have been receiving assistance, but from my point of view, I am eating independently." These notions of eating "independently" were further developed as follows.
When eating, Participant A's main concern was the food, its taste, and his ability to chew. As I observed every morning at his bedside, I noticed that when the nurse began assisting him with his meal, she was considerably slower than when she was performing her relatively fastpaced morning duties, which involved activities like mouth care, toilet support, and so forth. At this slower pace, without thinking, the nurse helped him move his mouth, brought food to it. Given this attention to the mouth and the slow, unthinking performance of the nurse, Participant $A$ was likely fully engaged in this sense of eating independently.

Participant C, a man in his 20s, also considered it important to eat independently. He typically spent most of the day in his power wheel chair and ate all three of his meals in the dining room, saying, "I can't stand it [asking for assistance with my meal]" and "I do not want to give up [eating by myself]." He eats his meals daily using a converted spoon, a system that he had arranged with his occupational therapist; this was done to respect his strong feelings about eating on his own, although a meal assistant would always watch him and help when he needed it. One day, the mother of another patient, who had come to assist with her son's eating in the dining room, said, upon seeing Participant $C$ eating in front of her, "Whenever I saw everyone trying so hard to eat on their own, I came back home thinking that I have to do my best." Thus, the participants' desire to eat independently was influenced not only by their strong wills, but also by the many kinds of support surrounding them such as nurses, occupational therapists, other staff, converted spoons, and even mothers of other patients, who did not support directly but rather in spirit.

\section{Learning to accept the PEG tube}

For Participant $\mathrm{B}$, an important eating habit that he had needed to form was being fed through a PEG tube. He related to me his experiences of "not having given up drinking" and "no longer having to eat or drink," both of which appeared to influence his decision to take the PEG tube. Participant $B$ is a man in his 50 s, who has spent about 40 years in the ward since he was hospitalized while in the sixth grade of elementary school. He was once very active in the ward, but recently has become bedridden; he now requires a $24 \mathrm{~h}$ NIPPV, and gets his three daily meals through a feeding tube. More recently, doctors have begun to encourage early operations, when the dysphagia is not as severe. Patients who are given PEG tubes early still typically eat using their mouths at least once a day, as Participant A did. However, gastrostomies - the making of an opening into the stomach often present serious problems for patients. Participant B said, "Medical care has progressed so much, and sometimes I have resisted it....The same thing happened with this gastrostomy. I was told to hurry up 
(and get it), but I hadn't yet given up drinking (fluids)." At the time of the study, Participant B was being fed through a PEG tube for all three meals a day. His feelings about it were as follows.

Participant B (B): In my case, eating itself was hard. Eventually, I could only drink nutritional supplements. But there was one time when the medicine (accidentally) entered my trachea, and I thought I was about to die. So when it was decided that I would be getting a PEG tube, I felt secure and happy, because I would no longer have to eat or drink. When eating became hard and I began drinking nutritional supplements, I had to drink around $200 \mathrm{ml}$ of those supplements, plus water and milk. I started getting pain in my stomach, because it would bloat. I gave it up when they told me that nasogastric feeding could be used if I could no longer drink nutritional supplements. Recently, more and more patients are being encouraged to get a PEG tube before their condition gets as bad as mine. I waited until the last moment to get one.

When Participant B was encouraged to take the PEG tube, he said, "... had not yet given up drinking." However, after experiencing the pain, suffering, and fear associated with attempting to eat, drinking heavy nutritional supplements, and nasogastric feeding, he began to accept the use of the PEG tube by degrees. The phrases, "eventually" and "so when..." showed that he had already understood why he needed to change his eating habits before he had even accepted the PEG tube.

When he decided to undergo the gastrostomy procedure, he felt "secure and happy." The word "secure" suggests that he was thinking of his past experiences of considerable pain and suffering from other eating methods; however, the word "happy," along with the statement, "...I would no longer have to eat or drink," suggests that he was also thinking of the future. Thus, he may have come to his decision to take a PEG tube by reconciling the vast number of experiences associated with eating from his past and future. After getting the tube, he compared his experience of the PEG tube with past eating experiences, and found that it was a positive experience.

In summary, Participant B related his experiences of "not having given up drinking" and "no longer having to eat or drink," both of which appeared to influence his decision to take the PEG tube. By holding on to these ambiguous and somewhat conflicting ideas, he was able to experience a number of procedures and eating arrangements, which ultimately led him to accepting the PEG tube. The experiences of Participant $D$ suggest that patients who took a PEG tube in the ward based their decision on not only their own subjective experiences, but also the experiences of other patients. Participant $D$ is a man in his 20s, who was admitted to the ward six years before the study period; he began using a PEG tube a few years ago, around the time doctors began to encourage its early use. He said about his decision, "I asked (my doctor) to give it (the PEG tube) to me. When I began to find it hard to drink much fluid, I saw other patients (like Participant B) who had already gotten the feeding tube, and thought that it might be easier for me. The PEG tube is much better now, because I know how painful it is to have a bloated stomach (from nutritional supplements)." That is, Participant D accepted the PEG tube not only because of his experiences with painful bloating, but also because he had observed other patients using the feeding tube.

\section{Alternative to having a meal}

Participant B cultivated a variety of new eating habits in response to the feeling that his tube feeding gave rise to new sensations in his stomach. For example, many of the bedridden patients in the muscular dystrophy ward watch TV cooking programs while they are being tube-fed at lunchtime. Participant B described his experience of watching cooking programs on TV during lunchtime as follows.

B: I wanted to watch TV cooking programs, something that I did not watch a lot of before (getting the PEG tube). People often tell me that they feel sorry for me, because even if I watch them, I cannot eat anything. However, this makes me want to watch these shows even more. It seems to produce gastric juice in my stomach even without me having an actual meal.

In addition, Participant $B$ wrote the following in his blog: "tube feeding tastes good." I decided to ask him about it again.

B: How can I say it, it might be a sensuous kind of thing. My stomach might be the signal.

I: Is it tasty?

B: It might be different from tasty; it's more like my stomach is filling up.

I: It would be nice if you could taste how good it is, and not just that it makes you full.

B: Again, how can I say it, it feels like stomach acid is produced when the formula enters my stomach.

I: You also said that this gastric acid comes out when you watch TV programs, but it's the same feeling as when the enteral formula enters the stomach, or someone is eating right next to you?

$B$ : I feel it the strongest when [the enteral formula] enters my stomach.

I: So you're fine with it. But even if you tell me that you don't care about it, I wouldn't feel so good eating right next to you.

B: I don't care about that at all, and in fact, I would rather see it.

I: So would you want me to eat right next to you?

B: If it looks tasty. I would like to see you enjoy your meal.

Participant $\mathrm{B}$ explained that he watched cooking 
programs because they made him feel as if his stomach was producing acid. In other words, he considered watching cooking programs as an alternative to having a meal, as evidenced by the production of extra stomach acid. In addition, the other alternatives included the enteral formula entering his stomach and seeing another person enjoy his or her meal. When I asked him about the "taste" of the enteral formula, which he had written about in his blog, he always prefaced his explanations with "it might be..." and "how can I say...." This uncertainty suggested that he considered the "sense" of the formula entering his stomach to be different from the conventional sense of something tasting good. However, he did not deny that it was not in some way tasty, suggesting that he felt some satisfaction from the tube feeding. His description of the experience of receiving the formula through the tube "my stomach is filling up," and "stomach acid is produced" indicate that he experienced sensations in his stomach that were entirely different from taste. As Merleau-Ponty $(1945,1962)$ pointed out, "The senses intercommunicate by opening on to the structure of the thing"; thus, for Participant B, the sensations of food tasting good intercommunicated with a number of other bodily sensations, giving rise to new "senses" in his stomach. This is further supported by his mentioning, "I feel hungry, but I don't want to eat," in a number of our other conversations.

Participant $D$ was the only one of his roommates, all of whom were roughly the same age as him, who took the PEG tube. For him, talking about food and watching cooking programs with his roommates had become his alternative to having a meal. One day, he began talking about food with one of his roommates who had just finished eating his lunch in the dining room and had come back to their room. While he was being fed through the PEG tube, Participant D asked, "Did you finish eating lunch? What did you eat for lunch?" In addition, when they rested on the bed after lunch, they both watched the same cooking programs and enjoyed talking about it with each other, exclaiming "Oh! Look!"; "Oh, that looks tasty!"; and "Yes!" In this way, their room was full of energy during the lunchtime break. Therefore, Participant D might have gotten some satisfaction by asking about the lunch menu, as well as watching the same cooking programs and talking about those programs with his roommates.

As seen, patients with muscular dystrophy who used a PEG tube related a number of alternatives to having a meal, including experiencing the unique, pleasant sensations in the stomach associated with tube feeding and bonding with roommates over lunchtime activities. Furthermore, they received some satisfaction from these alternatives, which eventually developed into eating habits for these patients.

\section{Using the feeding tube}

It was found that patients not only utilized the PEG tube passively, that is, for purely medical reasons but they also used it actively to enhance their quality of life in the ward. For instance, because Participant B spent $24 \mathrm{~h}$ a day lying on his hospital bed, his PC was one of the most important ways for him to connect to the outside world. He used the mouse by putting it on his abdomen and, through trial and error, determined the maximum amount of time he was physically able to use his computer. By not lying on his side and keeping himself in the supine position, he was able to extend the amount of time he could use the computer.

I: How did you figure out the best ways to use your computer without having to change the position of your body?

B: At first, I used the air mat. Then, I found two body positions that allowed me to extend my legs on both sides by putting my legs down and using big pillows. These two styles are fixed. I put a pillow behind my waist when I feel pain in my back. However, for me to do this, it is important to keep my weight constant. I feel pain in my tailbone when I start to lose weight. So, I increase the amount of formula from the feeding tube when my weight decreases and decrease the amount when my weight increases. My ideal variations in weight are within $1 \mathrm{~kg}$. In this way, tube feeding is useful for me.

Participant $\mathrm{B}$ found it important to control his weight by adjusting the amount of formula he received from the feeding tube, so that he could maintain the supine position and use his PC as much as possible every day. His methods of finding the best body position and weight control were developed through trial and error, as well as through asking for help from the staff and doctors. However, his frequent use of "I" indicated that he was the primary subject; furthermore, he did not refer at all to the staff or doctors in the quotation. I believe that this was because the staff and doctor were merely a part of his eating habits, and thus easy to ignore (see Participant A's description of eating independently). Nevertheless, he was only able to mention and fulfill the process because he was surrounded by staff that both heard and respected him.

Another instance of active use of the PEG tube was related to me by Participant E, a man in his 40 s. Although he could eat food using his mouth, he also used the PEG tube, which he took at around the same time that he underwent a bile stone operation, to take medicine for potassium deficiency. He said of this that, "It (the medicine) is active carbon, or charcoal. I take it through the PEG tube between meals. It can sometimes get lodged in your throat when you take it by mouth. It is difficult even for healthy people to take, (therefore, the PEG tube is convenient)." In other words, he used the $P E G$ tube to relieve his pain.

\section{DISCUSSION}

In this study, the eating experiences of a number of 
patients living in a muscular dystrophy ward was described, and these experiences analyzed from the perspective of the phenomenology of Merleau-Ponty. Typically, previous studies have described the lives of patients living in such wards for long periods only in terms of the anxiety and struggle they have undergone (Tsujino, 2005; Ito, 2008; 2010). In this study, while Participant $A$ reported on how difficult it was for him to move his mouth due to the progressive decline and the act of eating for Participant $A$ was also a chance to move his mouth and body, he felt happy when he was able to firmly chew his food. Furthermore, Participant B suffered from pain and fear before accepting a PEG tube, both he and Participant $D$ reported feelings of satisfaction from tube feeding.

Previous researchers took a primarily medical perspective of the eating behavior of patients with muscular dystrophy, focusing on ways to improve their ability to eat as their motor functions decline (Fujihara, 2010; Kawai et al., 2005; Konagaya et al., 2006; Yoshiga et al., 2010). Participant A became fully engaged in this sense of eating independently by giving his full attention to his mouth and because of the slow, unthinking performance of the nurse. When Participant $B$ used tube feeding to maintain his weight so that he could maximize his use of the PC, he considered staff members and the doctor who aided him as merely part of his eating habits. That is, the participants observed considered their eating behaviors to be independent activities, despite the daily role that attending nurses and doctors had in them.

Regarding tube feeding, a number of researchers have focused on the decision-making process associated with giving an elderly person a PEG, often demonstrating its particular difficulty (Brotherton and Abbott, 2009; Brotherton et al., 2007; Fairrow et al., 2004; Suganuma et al., 2009). Participant $A$ decided to use the PEG tube only after two years of consideration, and Participant B had not yet given up drinking when it was recommended to him. However, this study showed that the decisionmaking process of taking a PEG tube involves reconciling an enormous amount of previous experience with the future expectations associated with eating, including resolving ambiguous feelings such as "not giving up drinking yet" and "no longer having to eat or drink." Furthermore, after getting the PEG tube, participants in this study reported that they had formed new habits that brought them a similar amount of satisfaction as eating once had, such as pouring the formula into their feeding tubes, watching cooking programs, and observing other people's eating experiences. Engaging in such habits also appeared to give patients feelings of being full and that stomach acid was being produced, instead of merely giving them an experience of something as tasting good. The feeding tubes, in all, appeared to allow patients to live better lives.

In summary, this study showed that patients with muscular dystrophy had "cultivated habits" (Merleau-
Ponty, 1945, 1962) of eating according to their surrounding environment and in response to the increasing medical support and their progressive functional decline, instead of clinging to their past habits. With these new eating habits, their eating experiences came to be based on a "richer" perception of eating, one where food was viewed beyond merely its tasting good. It is thus important for nurses caring for patients with muscular dystrophy to understand what eating means to each patient; this would subsequently improve general medical care for these patients.

Recently, with the advance of medical technology, nurses in muscular dystrophy wards in Japan who have been playing a key role in providing sophisticated daily medical care to these patients as part of health care teams are apt to put more emphasis on preventing serious complications such as pneumonia and suffocation, rather than improving patients' satisfaction with eating. In addition, because of a general lack of qualified nurses working in these wards, nurses working with patients with muscular dystrophy are often heavily burdened by busy daily practice, and thus they cannot generally afford to give much thought to patients' desires for eating. Because patients with muscular dystrophy often have considerable difficulty eating, owing to the progression of their disorder, it cannot be denied that nurses should focus on preventing accidents.

However, it is hoped that this article can show that cultivating new attitudes and habits about eating will minimize the negative aspects of eating for patients with muscular dystrophy, such as its overall difficulty, the fear associated with it because of patients' progressive functional decline, and patients' resistance to tube feeding. By minimizing these negative aspects, meal times can become a more enjoyable and richer experience for patients with muscular dystrophy. Accordingly, by attending to patients' behavior, habits and desires related to eating, nurses can not only reduce the risk of pneumonia, but also understand and collaborate with the patients on how to make eating more meaningful, particularly for patients who find it difficult to eat or who have tube feeding. By giving thorough attention, nurses can think about and practice how best to help patients enjoy eating. Furthermore, this will ensure that nurses are in a better position to give good advice to young patients with muscular dystrophy who have a negative outlook on eating. It is thought that such nursing practice would not only prevent further eating problems, but also improve quality of life for patients in muscular dystrophy wards.

This study had some limitations. First, these data may have placed a disproportionate emphasis on the experiences of patients who have a relatively positive outlook on living in a muscular dystrophy ward. Furthermore, this study highlights the importance of describing the context of each patient's experiences. Therefore, five patients' experiences (mainly two) out of the nine participants 
observed was described and discussed.

\section{ACKNOWLEDGMENTS}

This research was funded by a grant from Sasagawa Memorial Health Foundation, the research promotion of improvement of QOL about hospice and palliative care in 2011, Japan. I am grateful to the study participants for cooperating in this study and acknowledge Yumi Nishimura for her help and advice at various stages of this article and also Yoshimi Endo and Yasuko Shimizu and for their valuable comments.

\section{REFERENCES}

Ahlström G, Gunnarsson LG (1996).Disability and quality of life in individuals with muscular dystrophies. Scand. J. Rehab. Med. 28:147-157.

Boström K, Ahlström G (2005). Living With a Hereditary Desease: Persons With Muscular Dystrophy and Their Next of Kin, Amer. J. Med. Genet. 136A:17-24

Brotherton A, Abbott A (2009). Clinical decision making and the provision of information in PEG feeding: an exploration of patients and their carers perceptions. J. Hum. Nutr. Dietet. 22:302-309.

Brotherton A, Abbott A, Hurley MA, Aggett PJ (2007). Home percutaneous endoscopic gastrostomy feeding: perceptions of patients, cares, nurses and dietitians. J. Adv. Nurs. 59:388-397.

Dreyer PS, Steffensen BF, Pedersen BD (2009). Life with home mechanical ventilation for young men with Duchenne muscular dystrophy. J. Adv. Nurs. 66(4):753-762.

Dubowitz V (2004). Muscle Disorders in childhood, $3^{\text {rd }}$ ed. London: Bailliere-Tindall.

Emery AE (2002). The muscular dystrophies. Lancet 359:687-95.

Fairrow AM, Mccallum TJ, Messinger-Rapport BJ (2004).Preference of older African-Americans for long-term tube feeding at the end of life. Aging Mental Health 8(6):530-534.

Fujihara A, (2010). Kinjisutorofuikanjaniokerushokujikeitai to sintaijyokyotonokanren [The relevance of pattern of meals and body situation of muscular dystrophy patients]. In Neuromuscular disease study group at the Ministry of Health and Welfare (Ed.), The proceeding of group meeting in 2010, Research on the multidisciplinary treatments of muscular dystrophy and the prevalence of research results by the expenses for commission of medical and neurological disease, 135.

Gibson BE, Nancy LY, Ross EG, Upshur PM (2007). Men on the margin: A Bourdieusian examination of living into adulthood with muscular dystrophy. Soc. Sci. Med. 65:505-517.

Gibson BE, Hilde Z, Patricia M (2009). 'Futureless persons': shifting life expectancies and the vicissitudes of progressive illness. Sociol. Health Illness 31(4):54-568.

Ishida E (2012). Life experiences of hospitalized adult patients in a muscular dystrophy ward -phenomenological description of time related experiences. J. Jpn Intractable Illness Nurs. Soc. 16(3):155165.

Ito K (2008). Kinjisutorofuikanja no Iryotekisekai [Medical World of the Patients of the Muscular Dystrophy].Gendaishiso 36(3):156-17.

Ito K (2010). Muscular Dystrophy Wards: Issues Related to Long-term Care Facilities in Japan. Core Ethics 25-36. Retrivedjuly 1, 2009, from cube.ritsumei.ac.jp/bitstream/10367/2431/1/ce6_25ik01.pdf

Kawai M, Ono M, Tanitabe K, Oya N, Saito T, Sugiyama H (2005). Kainyukokahantei no tame no Kinjisutorofui QOL hyokashakudo MDQol-60 no kaihatu [The development of MDQol-60 for the interposition evaluation]. In Neuromuscular disease study group at the Ministry of Health and Welfare (Ed), The Clinical Studies on Treatment and Medical Management of Muscular Dystrophy (2002-
2004). pp. 185-190.

Konagaya M, Inoue Y, Fujita I, Kuru S, Sakai M (2006). Changes of Subjective QOL in Duchenne Muscular Dystrophy from 1992 to 2004. IRYO 60(12):743-749.

Kohler M, Clarenbach CF, Böni L, Brack T, Russi EW, Bloch KE (2005). Quality of life, Physical Disability, and Respiratory Impairment in Duchenne Muscular Dystrophy. Amer. J. Respir. Critical Care Med. 172:1032-1036.

Masuda K, Masuda H (1993).Psychological study in patients with muscle disease-application of Szondi-Test-. IRYO 47(3):174-181.

Narayanaswami P, Bertorini TE, Pourmand R, Horner LH (2000). Longterm tracheostomy ventilation in neuromuscular diseases: patient acceptance and quality of life. Neurorehabil. Neural Repair 14(2):1359 .

Nätterlund B, Ahiström G (1999). Experience of social support in rehabilitation: a phenomenological study. J. Adv. Nurs. 30(6):13321340.

Nätterlund B, Ahiström G (2001).Activities of Daily living and Quality of life in Persons with Muscular Dystrophy. Scand. J. Rehab. Med. 33:206-211.

Nätterlund B, Sjoden PO, Ahiström G (2001). The illness experience of adult persons with muscular dystrophy. Disability Rehabil. 23(17):788-798.

Nutritional and Physical sectional committee, In Neuromuscular disease study group at the Ministry of Health and Welfare (Ed). (2007). The studies on the Optimal Environment in Medical Treatment and the Independence supporting method for muscular dystrophy patients. Dietary Education and Recipe for Muscular Dystrophy Patients, Japan.

Okumura T, Takagisi Y, Inagaki Y, Nakamura H (1997). A Study of Depression of the Hospitalized Children with Progressive Muscular Dystrophy -Using the Children's Depression Inventory (CDI). Child Health Res. 56(5), 674-677.

Omoto K, Oriyama H, Konagaya M (2010). Kinjisutorofuibyotokanjano jushokano jittaichosa[The field survey of severely impaired patients in muscular dystrophy wards], In Neuromuscular disease study group at the Ministry of Health and Welfare (Ed.), The proceeding of group meeting in 2010, Research on the multidisciplinary treatments of muscular dystrophy and the prevalence of research results by the expenses for commission of medical and neurological disease, 60 .

Pehler SR. Craft-Rosenberg M (2009). Longing: The Lived Experience of Spirituality in Adolescents with Duchenne Muscular Dystrophy. J. Pediatr. Nurs. 24(6):481-494.

Suganuma A, Matumura $\mathrm{Y}$, Miyaji N, Yamada $\mathrm{Y}$, Okuyama $\mathrm{M}$, Kakehashi C (2009) Irozosetsujutsuwouketakanja no kazoku no sinritekihenka [Psychological change of the family of the patients who got gastrostomy]. In Collection of papers in Japan caring institute: Geriatric Nurs. (1347-8249)39:47-49.

Tatara K, Jino S (2008). Kinjistorofui data base chosa [The study of data base for Muscular Dystrophy: the state of a muscular dystrophy ward]. In Neuromuscular disease study group at the Ministry of Health and Welfare (Ed), The Summary of Studies on the Optimal Environment in Medical Treatment and the Independence supporting method formuscular dystrophy patients (2005-2007):325-328.

Tsujino T (2005). On existential conflicts of patients with progressive muscular dystropy. Journal of Japanese Clinical Psychology, 23(3):294-304

Yoshiga M, Miyauchi M, Tanaka Y, Nakatani T, Tomii M (2010). EiyoKanriKeikakushokaramitaDuchennegataKinjisutorofuiKanja no EiyoJotai no genjo to kongo no kadai [The state and the assighnment of the nutrition condition of Duchenne Muscular Dystrophy from the perspective of the nutritional planning control]. In: Neuromuscular disease study group at the Ministry of Health and Welfare (Ed), The proceeding of group meeting in 2010, Research on the multidisciplinary treatments of muscular dystrophy and the prevalence of research results, 128 . 